\title{
Is the second internal thoracic artery better than the radial artery in total arterial off-pump coronary artery bypass grafting? A propensity score-matched follow-up study
}

\author{
Daniel Navia, MD, Mariano Vrancic, MD, Fernando Piccinini, MD, Mariano Camporrotondo, MD, \\ Jorge Thierer, MD, Christian Gil, MD, and Mariano Benzadon, MD
}

\begin{abstract}
Objective: The aim of our study was to evaluate the long-term outcome of patients exclusively undergoing total arterial revascularization off-pump coronary artery bypass grafting and to compare the performance of the radial artery and the right internal thoracic artery as a second conduit.
\end{abstract}

\begin{abstract}
Methods: We studied a consecutive series of 1700 patients undergoing off-pump coronary artery bypass grafting, receiving a radial artery or right internal thoracic artery as a second graft for total arterial revascularization, between 2003 and 2010. A total of 1447 patients $(85.11 \%)$ received bilateral internal thoracic artery grafting, and 253 patients $(14.89 \%)$ received left internal thoracic artery and radial artery grafting. A propensity scorematched analysis was performed to compare the 2 groups, bilateral internal thoracic artery and left internal thoracic artery and radial artery, relative to overall survival, morbidity, and combined end points event-free survival. Hazard ratios (HRs) and their 95\% confidence intervals (CIs) were estimated by Cox regression.
\end{abstract}

Results: In the full unmatched patient population, the postoperative survival (HR, 0.59; 95\% CI, 0.38-0.92; $P=.021$ ), incidence of reintervention/readmission (HR, $0.42 ; 95 \% \mathrm{CI}, 0.28-0.61 ; P<.001$ ), and combined end points (HR, $0.47 ; 95 \% \mathrm{CI}, 0.35-0.63 ; P<.001)$ were significantly better in the bilateral internal thoracic artery group. In the propensity score-matched patient population, the incidence of reintervention/readmission (HR, 0.40; 95\% CI, 0.18-0.88; $P=.02$ ) and combined end points (HR, 0.54; 95\% CI, 0.32-0.92; $P=.02$ ) were significantly better in the bilateral internal thoracic artery group compared with the left internal thoracic artery-radial artery group.

Conclusions: The results of our study provide evidence for the superiority of the right internal thoracic artery graft compared with the radial artery as a second conduit in total arterial revascularization off-pump coronary artery bypass grafting. (J Thorac Cardiovasc Surg 2014;147:632-8)

The beneficial effects after coronary artery bypass are directly related to the patency of the coronary grafts, but they also may be multifactorial. Use of bilateral internal thoracic artery (BITA) grafting rather than unilateral internal thoracic artery (ITA) grafting has been associated with increased survival and fewer cardiac events. ${ }^{1}$ In an attempt to maximize the use of arterial conduits on the presumption that these might yield a better outcome than vein grafts, arterial conduits such as the right internal thoracic artery (RITA) and the radial artery (RA) have been considered to be the logical step forward to revascularize the non-left anterior descending (LAD) coronary system. Clinical studies have documented equivalent long-term benefits with

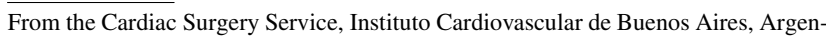
tina.

Disclosures: Authors have nothing to disclose with regard to commercial support. Received for publication Sept 5, 2012; revisions received Nov 14, 2012; accepted for publication Feb 12, 2013; available ahead of print April 8, 2013.

Address for reprints: Daniel Navia, MD, Instituto Cardiovascular de Buenos Aires,

Cardiac Surgery, Blanco Encalada 1543, 1428 Ciudad de Buenos Aires, Buenos

Aires, Argentina (E-mail: Navia.daniel@gmail.com).

$0022-5223 / \$ 36.00$

Copyright (c) 2014 by The American Association for Thoracic Surgery

http://dx.doi.org/10.1016/j.jtcvs.2013.02.012
RITA grafting to the left coronary system or the right coronary system with superior survival and lower need for further redo coronary artery bypass grafting $(\mathrm{CABG}){ }^{2-4}$

However, outcome studies investigating the RA as a second arterial bypass conduit show conflicting results. A retrospective angiographic study by Khot and colleagues ${ }^{5}$ demonstrated a significantly lower patency rate for the RA compared with ITA or even saphenous vein grafts (SVGs). In a prospective randomized clinical trial, Goldman and colleagues ${ }^{6}$ recently showed that the RA was not superior to the SVG relative to 1-year patency. However, Hayward and colleagues ${ }^{7}$ demonstrated that comparable angiographic and clinical outcomes can be achieved with any free arterial graft to the largest non-LAD target.

The aim of our analysis was to evaluate the long-term outcome of patients exclusively undergoing total arterial revascularization (TAR) off-pump coronary artery bypass (OPCAB), comparing the performance of the RA and the RITA as the second arterial graft.

\section{MATERIALS AND METHODS}

This is a retrospective analysis of prospectively gathered data over an 8 -year period of all patients undergoing OPCAB at the Institute 


\section{Abbreviations and Acronyms \\ BITA = bilateral internal thoracic artery \\ CABG = coronary artery bypass grafting \\ $\mathrm{CI}=$ confidence interval \\ euroSCORE $=$ European System for Cardiac \\ Operative Risk Evaluation \\ HR = hazard ratio \\ IQR $=$ interquartile range \\ ITA $=$ internal thoracic artery \\ LAD $\quad=$ left anterior descending \\ LITA $=$ left internal thoracic artery \\ $\mathrm{OPCAB}=$ off-pump coronary artery bypass \\ OR $=$ odds ratio \\ RA $\quad=$ radial artery \\ RITA $=$ right internal thoracic artery \\ SVG $\quad=$ saphenous vein graft \\ TAR $=$ total arterial revascularization}

Cardiovascular of Buenos Aires and who received TAR with left internal thoracic artery (LITA) grafting and a RITA or RA bypass as a second arterial conduit. From January 2003 to May 2011, a total of 1700 consecutive patients (of 1894) were scheduled for urgent or elective procedure undergoing TAR OPCAB and fulfilled the inclusion criteria of our observational study. A total of 1447 patients $(85.11 \%)$ received BITA grafting, and 253 patients $(14.89 \%)$ received LITA-RA grafting. All patient data were prospectively collected by using our custom-made database (Microsoft Access; Microsoft Corp, Redmond, Wash), which is used daily for clinical data management. Preoperative, operative, and postoperative data were obtained by retrospective review of clinical and pathology reports from the database and crosschecked with all medical charts. Two-dimensional biplane echocardiogram was used for left ventricular function evaluation. Moderate/severe left ventricular function was defined following Simpson's rule (ejection fraction $<35 \%$ ). Postoperative complications were defined as follows: myocardial infarction (new Q-wave or loss of R-wave progression across the chest leads or creatine kinase myocardial band enzyme $>10 \%$ ), low cardiac output (a newly placed intra-aortic balloon pump or use of inotropic drugs for $>48$ hours), bleeding requiring a rethoracotomy, mechanical ventilatory support more than 48 hours, or renal failure (creatinine $>2$ $\mathrm{mg} / \mathrm{dL}$ or $100 \%$ increase of the preoperative value, with or without the need of dialysis). Stroke was defined as a central neurologic deficit persisting for more than 24 hours or confirmed by computed tomography. Deep sternal wound infection was defined according to the evidence of mediastinitis during sternal reexploration. Operations in all the patients in this group were performed with the intention of carrying out the OPCAB (intention to treat), and the criteria used for conversion to on-pump CABG were hemodynamic or electric instability and calcified or intramyocardial coronary arteries.

Completeness of arterial revascularization was attempted in all cases and defined as all diseased coronary systems (stenosis $>70 \%$ ) receiving at least 1 arterial graft insertion. This relationship (graft insertion/lesion $>70 \%$ ) was evaluated for the LAD, circumflex artery, and right coronary artery systems in all patients. Hospital mortality and incidence of major complications (hospital mortality, myocardial infarction, renal failure, and stroke) were analyzed in both groups. Multivariate analysis was performed to identify independent predictors for the incidence of hospital mortality and major complications.

Late events were achieved by direct communication with the patient, their family, and attending physician, and medical records were revised.
The interview investigated the survival, the symptoms, the long-term medical management, the incidence of hospital readmissions or need for reintervention (percutaneous coronary intervention and redo CABG), and any operations-related complications. Data collected for readmissions included recurrent angina, new acute myocardial infarction, and congestive heart failure. A combined end points-free survival period at follow-up (mortality plus readmission/reintervention) also was considered. The institutional ethical committee approved the trial, and surgical consent was obtained from each patient with respect to surgical method and postoperative evaluations.

\section{Surgical Technique}

The surgical technique used for the OPCAB procedure has been reported $^{8}$ and consists of using both internal thoracic arteries (LITA-RITA) as exclusive conduits for coronary revascularization in the BITA group. Most ITA grafts were harvested in a skeletonized fashion, and the most commonly used technical configuration used was in situ anastomoses of the LITA to the LAD, and the RITA, after being divided at its origin, was connected end to side to the in situ LITA as a sequential T graft to the circumflex and right coronary arteries. In the LITA-RA group, the RA replaced the RITA graft and was also used as a sequential T graft from the LITA to the circumflex artery and the right coronary system. All sequential anastomosis were created as a diamond-shaped configuration. All RAs were harvested using an open surgical technique, and intraluminal irrigation with heparin and papaverine solution was used. No vein grafts or proximal anastomoses in the aorta were carried out in any of these patients.

\section{Propensity Score Matching and Statistical Analysis}

Propensity score matching was used to reduce the impact of treatment selection in comparing RA and RITA as the second conduit for TAR. Preoperative characteristics of patients in these study groups were summarized as mean \pm standard deviation, median and interquartile range (IQR), or prevalence (in percentage) as appropriate. Student $t$ test for independent sample or Mann-Whitney U test for continuous variables and chi-square tests for categoric variables were applied to examine differences between the BITA and LITA + RA groups. Variables revealing a $P$ value less than .2 in this analysis were entered into a logistic regression analysis with the use of the RA versus the RITA as the dependent variable. This was performed to generate a propensity score for each patient representing the probability to receive a RITA or RA as described by Puskas and colleagues ${ }^{9}$ and Emmert and colleagues. ${ }^{10}$

In our OPCAB experience, LITA-RA represents an earlier experience and BITA grafting came later. Because the operative eras were different, the date of surgery was incorporated into the propensity score. We divided the entire time frame of the study into quartiles, each including one quarter of the observations, and this parameter was one of the variables used to build the propensity score. The observations were then matched by propensity score within each quartile to ensure perfect matching time between cases with one or another type of surgery technique. The 4 considered time quartiles were (1) January 8, 2003, to March 25, 2005; (2) March 26, 2005, to November 28, 2006; (3) November 29, 2006, to December 29, 2008; and (4) December 30, 2008, to May 31, 2011. Five-digit matching without replacement was applied to form the matched sample. For each patient receiving BITA, 1 patient receiving LITA + RA was randomly selected in a 1:1 manner in case of an agreement of the propensity score ( 2 digits behind comma). The balance of measured variables between the study groups in the matched sample was assessed using a paired $t$ test or Wilcoxon test for continuous measures and the McNemar test for categoric measures. Kaplan-Meier analysis, together with log-rank testing, was used to evaluate the postoperative survival, readmission/reintervention, and combined end points-free survival in the full unmatched patient population. Finally, a Cox proportional hazards regression model was used to estimate the treatment effect and its statistical significance relative to cumulative survival, readmission/reintervention, and combined end points-free survival between the BITA and LITA + RA groups. 
TABLE 1. Preoperative characteristics of full unmatched patient population undergoing total arterial revascularization

\begin{tabular}{lccc}
\hline & $\begin{array}{c}\text { BITA } \\
(\mathbf{n}=\mathbf{1 4 4 7})\end{array}$ & $\begin{array}{c}\text { LITA-RA } \\
(\mathbf{n}=\mathbf{2 5 3})\end{array}$ & $\boldsymbol{P}$ value \\
\hline Age (y) & $63.3 \pm 9$ & $68.5 \pm 10$ & $<.0001$ \\
Male gender (\%) & 91.5 & 77.5 & $<.0001$ \\
Diabetes (\%) & 25.6 & 33.4 & .004 \\
HTA (\%) & 77.9 & 80 & .2 \\
Severe LVF (\%) & 19.7 & 35 & .0001 \\
Previous MI (\%) & 29.3 & 30 & .7 \\
Previous PCI (\%) & 22.5 & 23.1 & .4 \\
Previous CABG (\%) & 0.5 & 3.1 & $<.001$ \\
Previous class IV (NYHA) (\%) & 2.1 & 6.7 & $<.0001$ \\
Previous stroke (\%) & 3.5 & 3.5 & .5 \\
Aortic calcification (\%) & 2.2 & 5.5 & .006 \\
euroSCORE (mean) & $2.7 \pm 2.3$ & $4.8 \pm 3.3$ & .0001 \\
Previous renal disease (\%) & 4.2 & 6.3 & .2 \\
Previous IABP (\%) & 1.7 & 4.3 & .01 \\
Nonelective surgery (\%) & 33.5 & 46.6 & .0001 \\
Taking aspirin preoperatively (\%) & 78.8 & 45.9 & .0001 \\
Taking clopidogrel preoperatively (\%) & 12.2 & 14.6 & .3 \\
2-vessel disease (\%) & 18.2 & 21 & \\
Z3-vessel disease (\%) & 81.7 & 79 & .1 \\
Left main disease (\%) & 22.3 & 26.1 & .1 \\
No. of target vessels/patient (mean) & $2.84 \pm 0.5$ & $2.89 \pm 0.6$ & .2 \\
\hline BITA, Blat
\end{tabular}

BITA, Bilateral internal thoracic artery; LITA-RA, left internal thoracic artery-radial artery; $H T A$, arterial hypertension; $L V F$, left ventricular function; $M I$, myocardial infarction; $P C I$, percutaneous coronary intervention; $C A B G$, coronary artery bypass grafting; NYHA, New York Heart Association; euroSCORE, European System for Cardiac Operative Risk Evaluation; IABP, intra-aortic balloon pump.

\section{RESULTS \\ Patient Characteristics in the Full Unmatched Patient Population}

Table 1 shows the preoperative characteristics of the full unmatched study population. Patients in the BITA group were more likely to be male and significantly younger than patients receiving an RA as a concomitant second arterial conduit $(P<.0001)$. Patients in the LITA-RA group were more frequently diabetic and had a higher European System for Cardiac Operative Risk Evaluation (euroSCORE) than those in the BITA group $(P=.004$ and $P=.0001$, respectively). The prevalence of patients with impaired left ventricular function was higher in the LITA-RA group $(P=.0001)$. Nonelective procedures were significantly more frequent in the LITA-RA group, but this difference was neutralized in the propensity score-matched patient group. Other cardiovascular risk factors (eg, peripheral artery disease) or cerebrovascular morbidities did not differ significantly between treatment groups.

\section{Outcome in the Full Unmatched Patient Population}

The mean number of distal anastomosis per patient was $3.1 \pm 0.6$ in the BITA group and $2.7 \pm 0.5$ in the LITA-RA group $(P<.001)$. No central (aortic) anastomoses were performed in any group of patients. Both RITA and RA conduits were used as free grafts and anastomosed as a T graft into the LITA bypass. The right coronary artery/ posterior descending artery coronary system received a significantly higher number of bypasses with RITA than the RA conduit: $883(61.1 \%)$ versus $68(26.8 \%)(P=.0001)$. After reviewing all of the clinical records and operative notes, the right coronary artery/posterior descending artery was not revascularized in more than $70 \%$ of the cases for many reasons (diffuse disease, small diameter, no occlusion, or no severe stenosis). There were no differences in the number and types of bypasses performed for the diagonal and circumflex coronary systems between groups (Table 2).

The intraoperative and postoperative outcome data of the full unmatched patient population were evaluated. Skin-toskin time was longer in the BITA group than in the LITA-RA group $(199 \pm 38$ minutes vs $188 \pm 43$ minutes $)$ $(P<.0001)$, and $91.5 \%$ of the patients in the BITA group were extubated in the operative room versus $86 \%$ in the LITA-RA group $(P<.01)$.

In general, the LITA-RA group had a significantly worse postoperative outcome than the BITA group: Respiratory support more than 48 hours occurred in 17 patients $(6.7 \%)$ versus 32 patients $(2.2 \%)(P=.0001)$, low cardiac output occurred in 17 patients $(6.7 \%)$ versus 34 patients $(2.3 \%)(P=.001)$, stroke occurred in 4 patients $(1.5 \%)$ versus 6 patients $(0.4 \%)(P=.04)$, and renal dysfunction occurred in 12 patients $(4.7 \%)$ versus 19 patients $(1.3 \%)$ $(P<.001)$, respectively. Hospital mortality was higher in the LITA-RA group than in the BITA group: $15(5.9 \%)$ versus $20(1.3 \%)(P=.0001)$. Sternal wound infection with a need for surgical intervention was not significantly different between treatment groups (BITA $2.1 \%$ vs LITA-RA $1.4 \%, P=.6)$.

TABLE 2. Number of distal anastomosis for the different conduits and types of graft combinations (non-left internal thoracic artery/left anterior descending) performed

\begin{tabular}{lrcr}
\hline No. of distal anastomoses & LITA & RITA & Radial \\
\hline 1 & 1483 & 187 & 101 \\
2 & 215 & 987 & 147 \\
3 & & 277 & 5 \\
\hline
\end{tabular}

\begin{tabular}{lccc}
\hline \multicolumn{1}{c}{$\begin{array}{c}\text { Graft combinations } \\
\text { (non-LITA LAD) }\end{array}$} & RITA & Radial & $\boldsymbol{P}$ value \\
\hline $\mathrm{Dg}$ & $464(32 \%)$ & $60(23.7 \%)$ & .01 \\
$\mathrm{Cx}$ & $965(66.6 \%)$ & $192(75.8 \%)$ & \\
$\mathrm{Cx}-\mathrm{Cx}$ & $403(27.8 \%)$ & $51(20.1 \%)$ & .06 \\
$\mathrm{RCA} / \mathrm{PDA}$ & $883(61.1 \%)$ & $68(26.8 \%)$ & .0001 \\
No. of target vessels/ patient (mean) & $2.84 \pm 0.5$ & $2.89 \pm 0.6$ & .2 \\
Distal anastomosis/patient (mean) & $3.0 \pm 0.6$ & $2.7 \pm 0.6$ & $<.001$ \\
\hline
\end{tabular}

LITA, Left internal thoracic artery; RITA, right internal thoracic artery; $L A D$, left anterior descending; $D g$, diagonal; $C x$, circumflex; $R C A / P D A$, right coronary artery/ posterior descending artery. 
In multiple logistic regressions analysis, significant predictors for hospital mortality were age (odds ratio $[\mathrm{OR}], 1.09 ; 95 \%$ confidence interval $[\mathrm{CI}], 1.02-1.13$; $P<.0001$ ), severe left ventricular dysfunction (OR, 2.5; 95\% CI, 1.24-5.08; $P<.01)$, and nonelective surgery (OR, 10.3; 95\% CI, 3.9-26.9; $P=.0001$ ). The use of BITA was identified as protective for the incidence of major complications (OR, 0.634; 95\% CI, 0.41-0.96; $P=.03$ ).

Follow-up of hospital survivors $(\mathrm{n}=1665)$ was $94.1 \%$ complete $(\mathrm{n}=1568$; BITA: 1341 and LITA-RA: 227 patients). Median follow-up of all patients was 1364.5 days (IQR, 724-1984 days). Median follow-up of the BITA group was 1283 days (IQR, 697-1861 days). Median follow-up of the LITA-RA group was 2080 days (IQR, 1313-2587 days) $(P<.001)$. There was no difference in the proportion of patients with completed follow-up: BITA $94 \%$ versus LITA-RA $95.3 \%(P=.39)$.

There were $99(6.3 \%)$ late deaths during follow-up. Only 37 deaths $(2.3 \%)$ were due to cardiac causes (BITA: 24 patients vs LITA-RA: 13 patients; $P=.08$ ). Figure 1 shows the postoperative patient outcomes at 1,4 , and 7 years for the full unmatched patient population.

Postoperative survival was $99 \%, 94 \%$, and $90 \%$ in the BITA group and $97 \%, 91 \%$, and $83 \%$ in the LITA-RA group (log-rank: $P=.02$ ) (Figure $1, A$ ) (hazard ratio [HR], 0.59; 95\% CI, 0.38-0.92; $P=.021$ in the BITA group). Postoperative readmission/reintervention-free survival was $98 \%, 94 \%$, and $85 \%$ in the BITA group and $94 \%, 85 \%$, and $78 \%$ in the LITA-RA group (log-rank: $P=.00001$ ) (Figure 1, B) (HR, 0.42; 95\% CI, 0.28-0.61; $P<.001$ in the BITA group). Postoperative combined end point-free survival (mortality plus reintervention/readmission) was $97 \%, 89 \%$, and $66 \%$ in the BITA group and $92 \%, 77 \%$, and $53 \%$ in the LITA-RA group (log-rank: $P=.00001$ ) (Figure 1, C) (HR, 0.47; 95\% CI, 0.35-0.63; $P<.001$ in the BITA group). Overall, the BITA group had significantly better long-term outcomes than the LITA-RA group.

\section{Patient Characteristics in the Propensity Score-Matched Patient Population}

Table 3 shows the patient characteristics of the propensity score-matched population. Because of the significantly higher mean euroSCORE value in the LITA-RA group in the full unmatched patient population, the propensity score group turned out to be a high-risk group of patients, expressed by the high incidence of diabetes mellitus and severe left ventricular dysfunction, and the number of nonelective procedures. Postoperative cardiac-related deaths and complications were not significantly different between treatment groups. Hospital mortality was $4.03 \%$ in the BITA group and $3.36 \%$ in the LITA-RA group $(P=.5)$. Perioperative major complication rate was $10.7 \%$ in the BITA group and $9.40 \%$ in the LITA-RA group $(P=.5)$.

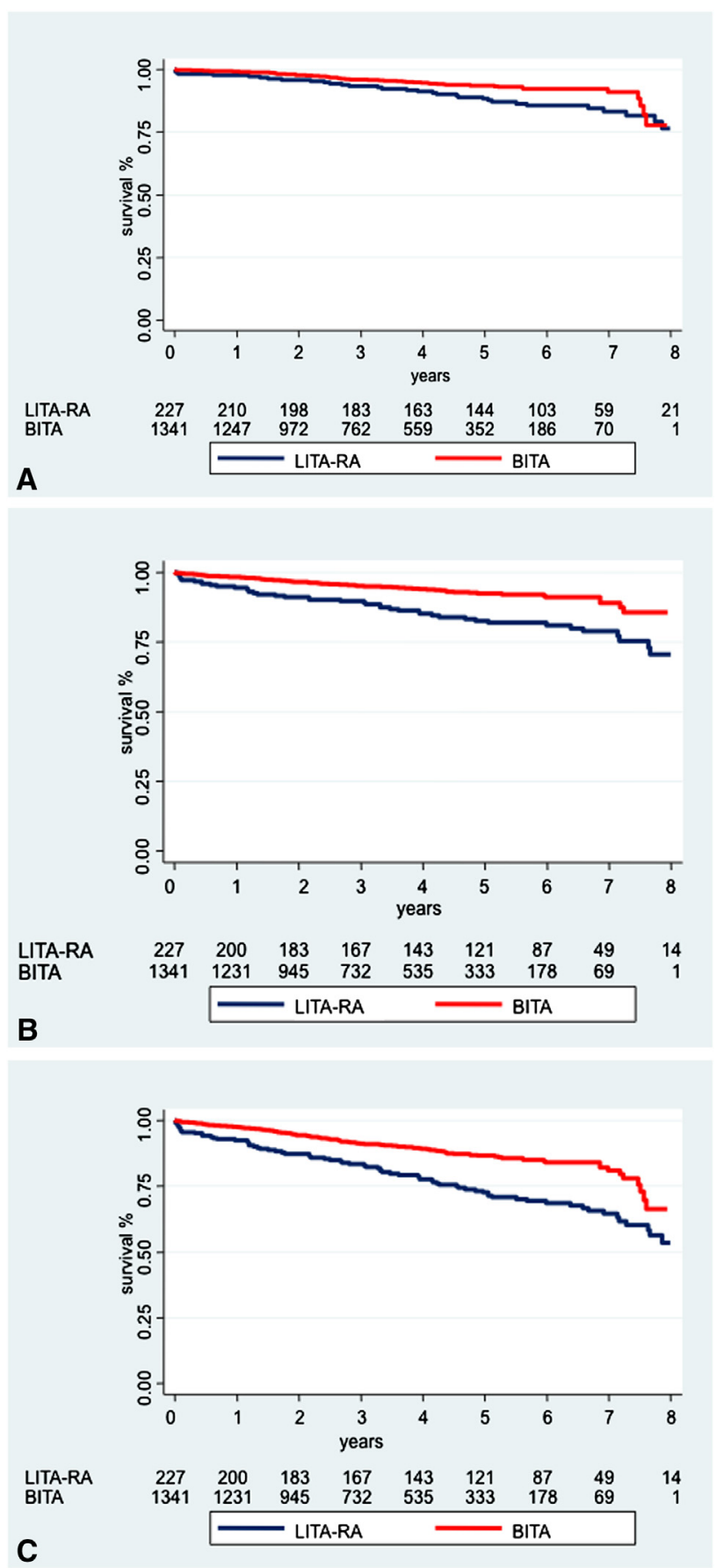

FIGURE 1. A, Survival after TAR OPCAB in the full unmatched patient population: BITA (red line) versus LITA-RA (blue line); logrank: $P=.02$. B, Postoperative readmission/reintervention-free survival after TAR OPCAB in the full unmatched patient population. BITA (red line) versus LITA-RA (blue line); log-rank: $P=.0001$. C, Postoperative combined end point-free survival (mortality plus reintervention/readmission) after TAR OPCAB in the full unmatched patient population: BITA (red line) versus LITA-RA (blue line); log-rank: $P<.0001$. $B I T A$, Bilateral internal thoracic artery; LITA, left internal thoracic artery; $R A$, radial artery. 
TABLE 3. Matched populations according to propensity variables and number of patients in each quartile

\begin{tabular}{|c|c|c|c|}
\hline & $\begin{array}{c}\text { BITA } \\
(\mathrm{n}=149)\end{array}$ & $\begin{array}{l}\text { LITA-RA } \\
(n=149)\end{array}$ & $P$ value \\
\hline Age $(y)$ & $68 \pm 8.4$ & $67 \pm 9.6$ & .81 \\
\hline Male (\%) & 82.5 & 81.2 & .44 \\
\hline Diabetes mellitus (\%) & 30.8 & 32.2 & .45 \\
\hline Severe LVF $(\%)$ & 30.2 & 30.2 & .55 \\
\hline euroSCORE (mean) & $3.9 \pm 2.4$ & $3.9 \pm 2.6$ & .49 \\
\hline $\begin{array}{l}\text { Preoperative renal } \\
\text { dysfunction }(\%)\end{array}$ & 6.2 & 4.2 & .44 \\
\hline Aortic calcification (\%) & 5.3 & 4.7 & .5 \\
\hline Prior coronary surgery $(\%)$ & 0.67 & 2.68 & .18 \\
\hline Preoperative hematocrit $(\%)$ & $39 \pm 4.4$ & $39 \pm 5.8$ & .65 \\
\hline Nonelective surgery (\%) & 39.60 & 37.58 & .42 \\
\hline$\geq 3$-vessel disease $(\%)$ & 85.91 & 79.19 & .085 \\
\hline No. of vessel disease & 2.96 & 2.91 & .76 \\
\hline Left main disease $(\%)$ & 24.8 & 21.5 & .49 \\
\hline First quartile (n) & 96 & 96 & \\
\hline Second quartile (n) & 45 & 45 & \\
\hline Third quartile (n) & 7 & 7 & \\
\hline Fourth quartile (n) & 1 & 1 & \\
\hline
\end{tabular}

There were $34(11.2 \%)$ late deaths during follow-up (BITA: 13 patients vs LITA-RA: 21 patients). Figure 2 shows the postoperative patient outcomes at 1,4 , and 7 years for the propensity score-matched group. Postoperative survival at 1,4 , and 7 years was $97 \%, 93 \%$, and $88 \%$, respectively, in the BITA group and $98 \%, 92 \%$ and $83 \%$, respectively, in the LITA-RA group (log-rank: $P=.65$ ) (Figure 2, A). Postoperative reintervention/ readmission-free survival at 1,4 , and 7 years was $97 \%$, $94 \%$, and $89 \%$, respectively, in the BITA group and $97 \%, 85 \%$, and $81 \%$, respectively in the LITA-RA group (log-rank: $P=.031$ ) (Figure 2, $B$ ). In multivariable analysis, BITA was the only independent predictor of reintervention/ readmission (HR, 0.40 ; 95\% CI, 0.18-0.88; $P=.02$ ). Postoperative combined end points-free survival (mortality plus reintervention/readmission) at 1,4 , and 7 years was $94 \%$, $88 \%$, and $80 \%$, respectively, in the BITA group and $95 \%, 79 \%$, and $66 \%$, respectively, in the LITA-RA group (log-rank: $P=.038$ ) (Figure $2, C$ ). In multivariable analysis, BITA (HR, 0.54; 95\% CI, 0.32-0.92; $P=.02$ ) and age in years (HR, $1.03 ; 95 \% \mathrm{CI}, 1.004-1.06 ; P=.02)$ were independently associated with this combined outcome.

Completeness of arterial revascularization was higher in the BITA group than in the LITA-RA group (mean number of distal anastomoses per patient $3.0 \pm 0.6$ vs $2.7 \pm 0.6$, $P<.001)$. There was a trend to higher relation grafts performed/number of diseased vessels in the BITA group: $1.07 \pm 0.39$ versus $0.99 \pm 0.39(P=.08)$. However, neither

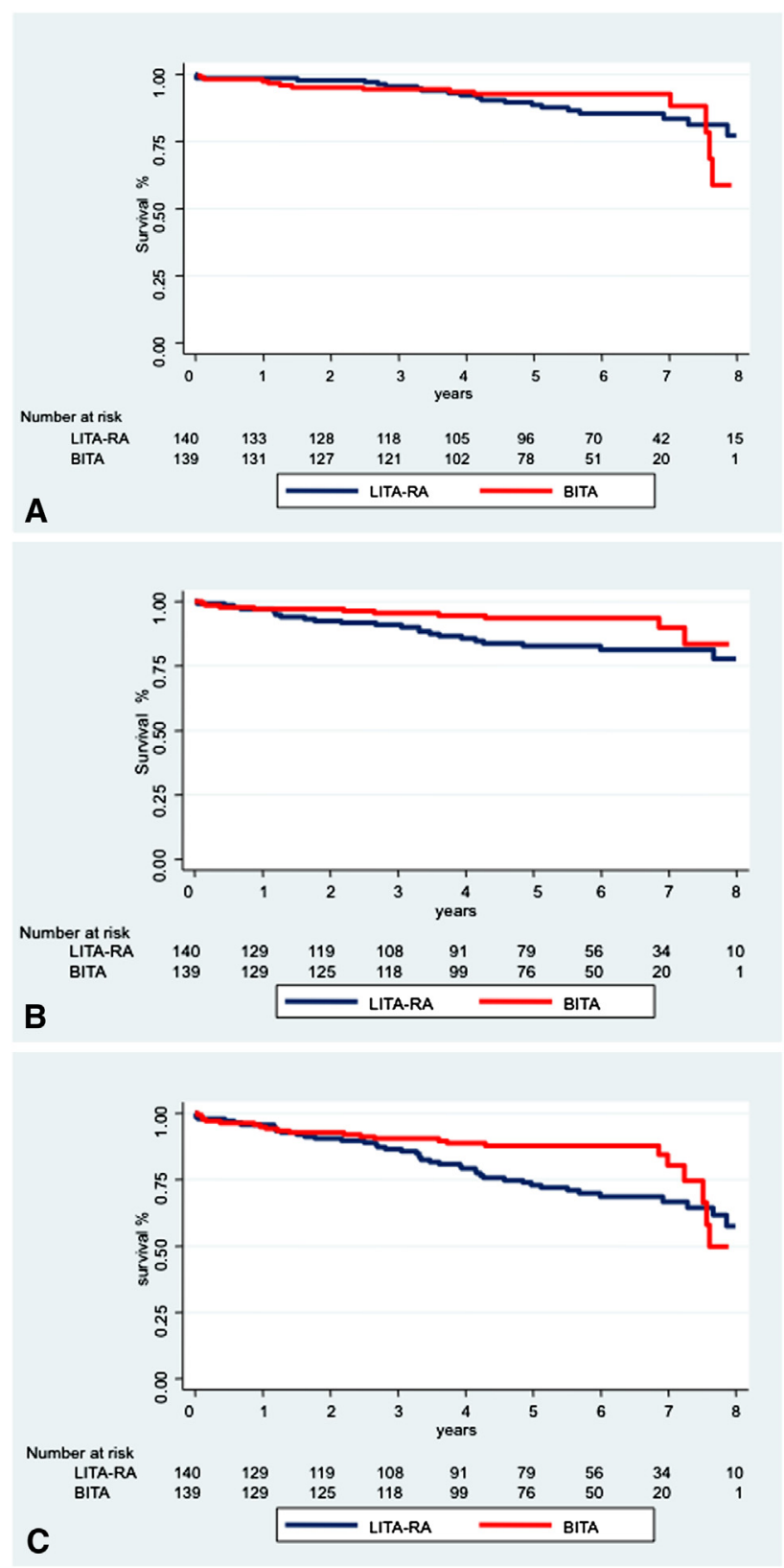

FIGURE 2. A, Survival after TAR OPCAB in the propensity scorematched patient population: BITA (red line) versus LITA-RA (blue line); log-rank: $P=.65 \mathrm{~B}$, Postoperative readmission/reintervention-free survival after TAR OPCAB in the propensity score-matched patient population: BITA (red line) versus LITA-RA (blue line); log-rank: $P=.031$. $\mathrm{C}$, Postoperative combined end point-free survival (mortality plus reintervention/readmission) after TAR OPCAB in the propensity score-matched patient population: BITA (red line) versus LITA-RA (blue line); log-rank: $P=.038$. BITA, Bilateral internal thoracic artery; LITA, left internal thoracic artery; $R A$, radial artery.

the mean number of bypasses (HR, $0.88 ; 95 \% \mathrm{CI}$, $0.44-1.75 ; P=.72$ ) nor the relation grafts performed per number of diseased vessels (HR, 0.70; 95\% CI, 
$0.20-2.43 ; P=.58)$ were identified as independent predictors of higher incidence of reintervention/readmission rate.

Overall, in this propensity score-matched population, the use of the RITA as a second arterial conduit in the BITA group had a significantly superior reintervention/readmission and combined end points-free survival outcomes than in the LITA-RA group.

\section{DISCUSSION}

The results of our study among 1700 patients provide evidence for the superiority of a RITA graft compared with the $\mathrm{RA}$ as a second conduit in TAR OPCAB and indicate that the RA is not an equal alternative conduit to the RITA relative to both survival and cardiac-related morbidity. The propensity score-matched approach showed significant advantages of the RITA procedure for the long-term outcome, expressed by a significantly superior readmission/reintervention and combined end points-free survival outcomes.

Basal clinical characteristics show that patients in the LITA-RA group were a significantly higher-risk population than the patients in the BITA group. Patients in the LITA-RA group were older, were more frequently female and diabetic, had more severe left ventricular dysfunction, had a history of NYHA class IV, and had a higher euroSCORE. Despite all of these factors, the initial differences were neutralized with the use of the propensity-score matched approach. In the unmatched group of patients, the LITA-RA group had significantly higher hospital mortality and major complications than the BITA group. The LITA-RA group represents our initial TAR OPCAB surgical experience, and some type of learning curve effect might be one of the possible explanations for these hospital results. The low incidence of stroke in both groups almost certainly reflects no aortic manipulation when a second ITA and RA are used as T grafts from the LITA. It is well known that aortic manipulation carries a substantial risk for stroke. ${ }^{11}$ In the propensity score-matched population, there was no difference inhospital mortality or the incidence of major complications.

Although the use of BITA has been considered a risk factor for sternal infection, especially in patients with diabetes, reduction of wound complications has been reported when the skeletonized technique is properly applied. ${ }^{12}$ In the present study, all ITAs were harvested using the skeletonized technique, and postoperative serum glucose was well controlled. The incidence of deep sternal infection in our series was low, without a significant difference between groups.

The main reason for the long-term benefit of BITA grafting lies in the anatomic structure of the ITAs, which are less susceptible to atherosclerosis than RAs. The lower capacity of nitric oxide release contributes to the susceptibility of the $\mathrm{RA}$ to atherosclerosis and is therefore responsible for the inferior long-term graft patency. ${ }^{13}$ Concerns about the longterm patency of the RA that support our findings have been raised by Ruttmann and colleagues ${ }^{4}$ and Khot and colleagues. ${ }^{5}$ In a multicenter randomized clinical trial (Radial Artery Patency Study), Deb and colleagues ${ }^{14}$ demonstrated a superior longitudinal angiographic patency rate of the RA compared with SVGs more than 5 years after surgery. In a randomized and well-done study, Hayward and colleagues ${ }^{15}$ demonstrated a good patency rate of the RA at a mean of 5.5 years angiographic follow-up control, without any difference in patency between the free RITA and the SVG. In the same study, the absolute survival (mean, 6.0 years) and event-free survival were equivalent between groups (RITA vs RA). In a randomized study comparing 4 different surgical strategies, Nasso and colleagues ${ }^{16}$ concluded that myocardial revascularization with 2 arterial conduits in multivessel coronary disease offers better event-free survival compared with a single arterial graft (LITA-LAD strategy), irrespective of which conduit is used as a second-choice arterial graft (RITA or RA) + SVG. There were several differences in these studies compared with our work ${ }^{15}$ : An onpump technique was used; the rates of TAR were $30.3 \%$ and $27.0 \%$ for the RA and RITA groups, respectively; sequential graft configurations were not allowed in either of the studies ${ }^{14,15} ; 1$ or more supplementary vein grafts were used; and proximal anastomoses were to the aorta, which may explain the higher incidence of postoperative stroke. In the latter study, ${ }^{16}$ there was an inferior mean number of grafts per patient performed to the aorta, with a relative short-term follow-up (mean, 2 years). These differences make it impossible to draw any definitive conclusions regarding the equivalent performances of the 2 arterial conduits in the long-term follow-up.

In our series of TAR OPCAB, patients in the LITA-RA group had inferior reintervention/readmission and combined end points-free survival outcomes than patients in the BITA group. These surgical techniques have been used by our group as routine procedures since 2002 and allow us to avoid performing the proximal anastomosis over the ascending aorta and at the same time to obtain more length of the arterial conduits used to perform sequential anastomosis. With the use of this T-graft technique, double sequential grafts to the circumflex coronary artery was feasible in more than $25 \%$ of the cases.

The addition of off-pump techniques to this approach creates a more technically demanding procedure. ${ }^{8}$ OPCAB offers superior postoperative outcomes with regard to major cerebrovascular and cardiac complications ${ }^{9,17,18}$ and disproportional benefits in high-risk patients. ${ }^{10}$ The combination of an aortic, no-touch strategy with the TAR techniques used in this series can effectively reduce neurologic complications while yielding excellent long-term outcomes. ${ }^{19-21}$

Furthermore, off-pump surgery has been repeatedly criticized to come at a cost of less complete revascularization, suggesting that it is not preferable in patients with multivessel disease. ${ }^{22-24}$ In our series, this surgical strategy 
allowed us to perform a high rate of complete arterial revascularizations in both groups of patients.

\section{Study Limitations}

This is a retrospective study, and although the propensity score-matching algorithm produced rather comparable groups, the study was not randomized, and we cannot rule out additional effects of missing covariates. In addition, the study period was long and most of the LITA-RA offpump procedures were performed in the earlier part of the study, and BITA experience comes later. Despite the use of propensity score analysis, this issue may have played a role in the final results. The longer follow-up of patients in the LITA-RA group compared with the BITA group is a further limitation for the interpretation of the findings. However, despite the shorter follow-up, there is a clear difference in long-term outcomes supporting a benefit of using the RITA as a second arterial graft.

\section{CONCLUSIONS}

In view of our study results, the second ITA graft should be used more frequently for $\mathrm{CABG}$ in the future. The use of the RITA may extend the benefits of TAR to a larger population undergoing $\mathrm{OPCAB}$ surgery, producing better longterm results even though the initial operation is longer and technically more demanding.

\section{References}

1. Lytle BW, Blackstone EH, Loop FD, Houghtaling PL, Arnold JH, Akhrass R, et al. Two internal thoracic arteries are better than one. J Thorac Cardiovasc Surg. 1999; 117:855-72.

2. Sabik JF, Stockins A, Nowicki ER, Blackstone EH, Houghtaling PL, Lytle BW, et al. Does location of the second internal thoracic artery graft influence outcome of coronary artery bypass grafting? Circulation. 2008;118(Suppl):210-5.

3. Grau JB, Ferrari G, Mak AW, Shaw RE, Brizzio ME, Mindich BP, et al. Propensity matched analysis of bilateral internal mammary artery versus single left internal mammary artery grafting at 17-year follow-up: validation of a contemporary surgical experience. Eur J Cardiothoracic Surg. 2012;41:770-6.

4. Ruttmann E, Fischler N, Sakic A, Chevtchik O, Alber H, Schistek R, et al. Second internal thoracic artery versus radial artery in coronary artery bypass grafting: a long-term, propensity score-matched follow-up study. Circulation. 2011; 124:1321-9.

5. Khot UN, Friedman DT, Petterson G, Smedira NG, Li J, Ellis SG. Radial artery bypass grafts have an increased occurrence of angiographically severe stenosis and occlusion with left internal mammary arteries and saphenous vein grafts. Circulation. 2004;109:2086-91.

6. Goldman S, Sethi GK, Thai H, McFalls E, Ward HB, Kelly RF, et al. Radial artery grafts vs saphenous vein grafts in coronary bypass surgery: a randomized trial. JAMA. 2011;305:167-74.

7. Hayward PA, Gordon IR, Hare DL, Matalanis G, Horrigan ML, Rosalion A, et al. Comparable patencies of the radial artery and right internal thoracic artery or saphenous vein beyond 5 years: results from the Radial Artery Patency and Clinical Outcomes trial. J Thorac Cardiovasc Surg. 2010;139:60-7.

8. Navia D, Vrancic M, Vaccarino G, Piccinini F, Raich H, Florit S, et al. Total arterial off-pump coronary revascularization using bilateral internal thoracic arteries in triple-vessel disease: surgical technique and clinical outcomes. Ann Thorac Surg. 2008;86:524-30.

9. Puskas JD, Kilgo PD, Lattouf OM, Thourani VH, Cooper WA, Vassiliades TA, et al. Off-pump coronary bypass provides reduced mortality and morbidity and equivalent 10-year survival. Ann Thorac Surg. 2008;86:1139-46.

10. Emmert MY, Seifert B, Wilhelm M, Grunenfelder J, Falk V, Salzberg SP. Aortic no-touch technique makes the difference in off-pump coronary artery bypass grafting. J Thorac Cardiovasc Surg. 2011;142:1499-506.

11. Hangler HB, Nagele G, Danzmayr M, Muller L, Ruttmann E, Laufer G, et al. Modification of surgical technique for ascending aortic sclerosis: impact on stroke reduction in coronary artery bypass grafting. J Thorac Cardiovasc Surg. 2003;125:391-400.

12. Calafiore AM, Vitolla G, Iaco AL, Fino C, Di Giammarco G, Marchesani F, et al. Bilateral internal mammary artery grafting: midterm results of pedicled versus skeletonized conduits. Ann Thorac Surg. 1999;67:1637-42.

13. He GW, Liu ZG. Comparison of nitric oxide release and endothelium-derived hyperpolarizing factor-mediated hyperpolarization between human radial and internal mammary arteries. Circulation. 2001;104(Suppl):I344-9.

14. Deb S, Cohen EA, Singh SK, Une D, Laupacis A, Fremes SE. RAPS Investigators. Radial artery and saphenous vein patency more than 5 years after coronary artery bypass surgery: results from RAPS (Radial Artery Patency Study). J Am Coll Cardiol. 2012;60:28-35.

15. Hayward PA, Hare DL, Gordon I, Matalanis G, Buxton BF. Which arterial conduit? radial artery versus free right internal thoracic artery: six-year clinical results of a randomized controlled trial. Ann Thorac Surg. 2007;84:493-7.

16. Nasso G, Coppola R, Bonifazi R, Piancone F, Bozzetti G, Speziale G. Arterial revascularization in primary coronary artery bypass grafting: direct comparison of 4 strategies-results of the Stand-in-Y Mammary Study. J Thorac Cardiovasc Surg. 2009;137:1093-100.

17. Tarrío RF, Cuenca JJ, Gomes V, Campos V, Herrera JM, Rodríguez F, et al. Offpump total arterial revascularization: our experience. J Card Surg. 2004;19: 389-95.

18. Sedrakyan A, Wu AW, Parashar A, Bass EB, Treasure T. Off-pump surgery is associated with reduced occurrence of stroke and other morbidity as compared with traditional coronary artery bypass grafting: a meta-analysis of systematically reviewed trials. Stroke. 2006;37:2759-69.

19. Puskas JD, Thourani VH, Kilgo P, Cooper W, Vassiliades T, Vega JD, et al. Offpump coronary artery bypass disproportionately benefits high-risk patients. Ann Thorac Surg. 2009;88:1142-7.

20. Bolotin G, Shapira Y, Gotler Y, Frolkis IV, Ben-Gal Y, Nesher N, et al. The potential advantage of no-touch aortic technique in off-pump complete arterial revascularization. Int J Cardiol. 2007;114:11-5.

21. Edelman JJ, Yan TD, Bannon PG, Wilson MK, Vallely MP. Coronary artery bypass grafting with and without manipulation of the ascending aorta-a meta-analysis. Heart Lung Circ. 2011;20:318-24.

22. Halbersma WB, Arrigoni SC, Mecozzi G, Grandjean JG, Kappetein AP, van der Palen J, et al. Four-year outcome of OPCAB no-touch with total arterial Y-graft: making the best treatment a daily practice. Ann Thorac Surg. 2009; 88:796-801.

23. Moller CH, Perko MJ, Lund JT, Andersen LW, Kelbaek H, Madsen JK, et al. Three-year follow-up in a subset of high-risk patients randomly assigned to off-pump versus on-pump coronary artery bypass surgery: the Best Bypass Surgery trial. Heart. 2011;97:907-13.

24. Filardo G, Grayburn PA, Hamilton C, Hebeler RF Jr, Cooksey WB, Hamman B. Comparing long-term survival between patients undergoing offpump and on-pump coronary artery bypass graft operations. Ann Thorac Surg. 2011;92:571-8. 